\title{
Arbor
}

\section{El cambio familiar en España en el marco de la evolución histórica}

\author{
David Reher
}

Arbor CLXXVIII, 702 (Junio 2004), 187-203 pp.

\section{Cambios y continuidades desde una perspectiva histórica}

La población y los distintos retos relacionados con ella constituyen uno de los temas sociales claves que tiene y tendrá ante sí la sociedad española. En los próximos años, incluso décadas, varios de los retos más importantes que la sociedad tiene están relacionados directamente con la población. Migraciones, envejecimiento, sistemas de pensiones, reproducción y familia, salud; todos ellos constituyen aspectos fundamentales de cara al bienestar de la sociedad, y todos ellos están íntimamente relacionado con la población y su estudio.

El tema de las formas familiares y su desarrollo en España se puede abordar desde un marco histórico de análisis ya que ayuda a facilitar una comprensión más dimensionada de los procesos recientes de transformación que siguen en curso. La perspectiva histórica, al estar algo distante en el tiempo, resta inmediatez en nuestros análisis y permite ver cambios recientes de forma más sosegada. No es la única perspectiva posible, pero considero que es muy útil. Constituye un buen complemento a los análisis más pegados a la actualidad, propios, por ejemplo, de la sociología.

En los años recientes la familia se ha convertido en objeto de preocupación dentro de la sociedad española. Esta preocupación a veces se carga de tintes de crisis y de decadencia. Se habla mucho de la crisis de la familia actual, del declive de la autoridad paterna y de los valores que sustentan a la familia, de la incapacidad de la familia para llevar a cabo adecuadamente la tarea de educar a sus hijos, del abandono por parte de las mujeres de su papel tradicional como vertebradoras del hogar a favor 
de una actividad cada vez mayor dentro del mercado de trabajo, de las familias que no parecen ya saber socializar a sus hijos ni disciplinarlos, dejando esa tarea en manos de la televisión o de los profesores de educación primaria y secundaria, del fin de la familia como motor capaz de cubrir las necesidades reproductivas de la sociedad, de la falta de respeto de los jóvenes hacia el matrimonio, sustituyéndolo por la cohabitación y, cuando hay hijos, éstos nacen fuera del matrimonio. En fin, muchas preocupaciones que suenan, salen en la prensa y hacen pensar como si hubiéramos pasado en España de una situación de una familia tradicional, capaz de justificar las más duras de las políticas, a otra familia apenas reconocible, secuestrada por modas y por realidades contemporáneas.

Se trata de un panorama nada optimista. Si a ello se le añade la creciente preocupación social por la falta de nacimientos en el país, realidad íntimamente ligada a la familia, no es difícil comprender esta preocupación social. Ante esto yo creo que cabe preguntarse si la realidad actual de la familia en España es tan negativa como parecerían indicar estos hechos. Es útil a veces tener una perspectiva un poco menos inmediata, más distante, más histórica, a fin de poder comprender algo mejor las distintas transformaciones que están ocurriendo, con el propósito de separar los cambios puntuales de los de verdadera alcance.

En las últimas décadas se pueden detectar importantes cambios, aunque también importantes continuidades en las formas familiares. Aunque los cambios hayan sido enormes, paralelos en muchos sentidos a los procesos de modernización de la sociedad, todavía es posible detectar muchos elementos de la familia tradicional en España. Se trata de una familia tradicional que sigue siendo perfectamente identificable dentro del conjunto europeo, como siempre lo ha sido. Entonces, pues, tenemos esta mezcla de cambios brutales junto con continuidades notables.

En el siglo XX, y sobre todo durante su segunda mitad, se han producido profundas transformaciones sociales y económicas en España. Recordemos que en el citado siglo el ritmo de cambio social ha sido tal vez más intenso que en cualquier época del pasado. En 1900 España era un país bastante pobre, con niveles muy elevados de mortalidad y de fecundidad, un país eminentemente rural (más del $60 \%$ de la población vivía en el campo), con una producción económica en el mundo rural destinada en parte no despreciable al autoconsumo. Se trataba de un país con un bajo nivel educativo, mucho analfabetismo (pero con grandes variaciones regionales y por sexo). En el tramo final del siglo, el régimen demográfico era totalmente distinto. Se trataba de una sociedad urbana, con una economía destinada en buena medida a la exportación, con unos 
El cambio familiar en España en el marco de la ...

niveles de educación comparables a los de los países del norte de Europa y con una sociedad de consumo bien asentada. Fue el gran siglo de modernización y de cambio social. No cabe subestimar la importancia de este proceso.

Forzosamente, la familia no podía quedar al margen de todo ello y efectivamente fue también un siglo de enormes transformaciones en la institución familiar. Conviene enumerar aquí algunos de los más significativos que hayan afectado a la familia. Aún con el riesgo de simplificar en exceso, se puede hablar de las cuatro de las principales transformaciones ocurridas en la segunda mitad del siglo XX que hayan afectado a la familia en España.

Desde una perspectiva estrictamente histórica, la pérdida de relevancia social de los grandes sistemas familiares, uno de ellos basado en la sucesión divisible y otro en la sucesión indivisible del patrimonio familiar -la familia nuclear frente a la familia troncal- constituye el cambio de mayor alcance. Esta pérdida de importancia de estas grandes formas de organizar la vida familiar en España se debe más a transformaciones sociales, económicas y demográficas en España que a cualquier proceso legislativo o de reforma. Se trata de sistemas de familia que perdieron su vigencia definitoria sin conflictos, sin revueltas, sin apenas debates. Aunque desde la perspectiva de ahora pueda parecer una transformación algo menos importante que otras, no cabe duda de que alteró profundamente lo había sido durante siglos uno de los ejes centrales de la familia y de la sociedad españolas.

El segundo gran cambio ha sido la profunda transformación del régimen demográfico que gobierna la reproducción de las familias españolas. Conviene tener presente que esta transformación ha tenido dos fases claramente distintas. Hay una primera fase tendente a mejorar, en palabras de Massimo Livi Bacci, «la eficacia» en materia reproductiva, seguida de otra fase caracterizada por un verdadero descalabro, un desfondamiento de los niveles de fecundidad, donde se da la reducción drástica de una de las funciones que tradicionalmente se consideraba prioritaria de la familia, la de asegurar la reproducción demográfica de la sociedad.

La primera fase de esta transformación consistió en una reducción del esfuerzo, en términos de tiempo y de desgaste físico, que precisaban las familias para satisfacer sus propias pretensiones reproductivas: disminuyó la mortalidad en la infancia y disminuyó la fecundidad de las mujeres. Tener una familia pasó de ocupar múltiples partos y veinticinco años de la vida de una mujer a ocupar sólo una pequeña parte de ese es- 


\section{David Reher}

pacio de tiempo. Ese proceso se había iniciado a principios de siglo y culminó en la década de 1970 cuando España por fin había superado su déficit demográfico con respecto a los países del Norte de Europa, con una mortalidad perfectamente comparable y una fecundidad, si bien todavía bastante alta, dentro de lo que podríamos considerar normal para la época. Esta transformación animó a las familias a invertir más en sus hijos, a tener lo que llaman los demógrafos «hijos de calidad», con las consabidas implicaciones para los sistemas educativos y para el crecimiento económico del país. De hecho, a pesar de una mayor «eficacia» del régimen demográfico, con toda probabilidad el coste estrictamente económico de tener una familia aumentó significativamente, debido precisamente a estas inversiones. Esta fue la primera fase del gran cambio demográfico. La segunda fase se ha dado en los últimos treinta años, cuando esa mayor eficacia reproductiva se ha transformado en un desplome de la fecundidad, con enormes consecuencias tanto para la sociedad como para las familias. A partir de 1980 en España la fecundidad se situó en niveles jamás conocidos históricamente. Se trata de un cambio que tiene y tendrá importantes implicaciones para la sociedad en las décadas venideras.

En términos generales, tanto en lo que se refiere a la primera fase como la segunda de esta transformación demográfica, España sigue un camino similar al de otros países de nuestro entorno europeo. Puestos a señalar especifidades españolas en este proceso, cabe enfatizar que España suele llegar tarde a estos fenómenos, pero los experimenta con mucha rapidez e intensidad, más que otros países de nuestro entorno. Esta característica está presente en otras transformaciones y puede considerarse realmente «española». Tiene implicaciones para las formas en las que se desarrollan estos procesos de cambio social.

El tercer gran cambio en la familia ocurrido en el siglo XX, sobre todo en su segunda mitad, y relacionado al menos indirectamente con el punto anterior, consiste en el rápido aumento en la participación laboral de las mujeres. Empujadas en parte por las realidades económicas y por las aspiraciones de sus propias familias, y animadas a ocupar un papel social muy distinto al vigente en el pasado, a partir de la década de los 1970 las mujeres entraron masivamente en el mercado de trabajo, produciendo aumentos verdaderamente espectaculares en sus tasas de actividad económica. De hecho, se trata de un proceso similar al que se produce en toda Europa, aunque más tardíamente y tal vez con mayor rapidez en España. Esta participación laboral de la mujer ha tenido enormes efectos sociales y económicos. En cuanto a la familia, ha supuesto la eliminación efectiva 
de la madre como referente fundamental y única de la familia. Se trata de un cambio de tal magnitud que no podía dejar sin tocar una institución como la familia, obligando, dicho sea de paso, a todos los miembros del grupo familiar, y por supuesto a la sociedad, a modificar sus comportamientos tradicionales, empezando por las madres mismas. Ha tenido, claro está, efectos económicos beneficiosos para las economías familiares, ha sido un factor no despreciable en el auge del desempleo en España en los últimos treinta años, y ha hecho mucho más compleja la vida de las madres trabajadoras y la de sus parejas y sus hijos.

El cuarto gran cambio ocurrido en el siglo XX ha sido que el Estado ha ido ocupando cada vez mayores esferas de la vida, esferas que tradicionalmente correspondían a la familia. Cabe citar dos ejemplos claros y muy conocidos al respecto. Por un lado, en el terreno de la educación y la socialización de los niños, la familia ha terminado cediendo protagonismo al Estado, a la escuela y a los medios de comunicación. Se trata de una cesión, ya en marcha tímidamente desde finales del siglo XIX, que no hizo más que acelerarse con la entrada masiva de las mujeres en el mercado de trabajo. Algo que antiguamente correspondía en su gran mayoría a la familia ahora es sólo en parte parcela de la misma. El otro ejemplo, igualmente elocuente, de este proceso ha sido la implementación de un sistema público de salud y, sobre todo, de pensiones, hecho que ha alterado de manera fundamental uno de los papeles más tradicionales de la familia. A partir de ahora, en su tarea de socorrer a sus propios necesitados, sobre todo a los ancianos, la familia pasó a tener un aliado importante en el Estado.

He aquí cuatro grandes transformaciones que han afectado a la familia, a la institución familiar durante el siglo XX. No cabe entender estos cambios de forma aislada. Forman parte de otras transformaciones económicas, sociales, culturales y políticas que también han afectado a la sociedad española. Juntos constituyen el gran proceso modernizador que ha caracterizado al siglo XX europeo. Como a menudo ocurre, tampoco han sido específicamente españolas, aunque su calendario preciso, así como su intensidad, sí que eran hasta cierto punto específicamente españolas.

Ahora bien, no todo han sido cambios. La realidad de la familia en España también muestra grandes y notables continuidades a lo largo del siglo XX, especialmente visibles muchas de ellas en su último tramo. Desde hace siglos, la familia española ha sido una institución, muchas de cuyas características principales se han distinguido de forma notable de la institución familiar vigente en el norte de Europa. En otra parte yo he escrito sobre la existencia de una familia «fuerte», ubicada en el sur del continen- 
te europeo, donde tendía a primar la familia sobre el individuo, frente a una familia «débil», característica en buena parte del centro y del norte de Europa, donde lo individual tendía a primar sobre lo familiar ${ }^{1}$. Estas formas distintas, norte-sur/débil-fuerte, de vivir la familia, que probablemente datan al menos desde la Edad Media, terminan marcando las formas familiares contemporáneas, de tal modo que las diferencias espaciales en Europa no sólo no han desaparecido sino incluso, en términos relativos, se han ampliado en muchas ocasiones. Ello no significa que no se hayan producido cambios importantes en los regímenes familiares - que los ha habido y son muchos y muy importantes- sino que no han servido para borrar esta distinción tan importante entre las distintas formas de entender la familia en el continente europeo. Así pues, también cabe hablar de importantes continuidades en la institución familiar, no sólo en cuanto a su distribución básica en Europa, sino también a lo largo del tiempo. Quisiera a continuación dar algunos ejemplos de estas continuidades.

El primero es que en España, desde siempre y también en la actualidad, la familia interviene muy activamente en asegurar el bienestar de sus miembros, sobre todo los miembros vulnerables. Cabe mencionar tres ejemplos de ello.

Para empezar, la atención a los ancianos en España en la actualidad es mucho más activa que en los países del norte de Europa. Parece que ha sido siempre más activo el papel de la familia «fuerte» del sur de Europa de cara a los ancianos, desde como mínimo el siglo XVIII. De ahí la proporción de ancianos en instituciones es relativamente baja en España, aunque va en aumento, como no podía ser de otra manera. Los ancianos en contacto habitual con sus hijos, bien mediante la corresidencia, la proximidad residencial o las visitas frecuentes, es una situación habitual en España, tanto ahora como en el pasado. La frecuencia e intensidad de estos contactos que se dan aquí no parecen tener comparación con los habituales en el norte de Europa. Por ejemplo, de acuerdo con el censo de 1991 en España, un 44 por cien de la población >60 seguía residiendo con algún hijo, porcentaje muy superior a la existente en Europa. En el sur del continente, en una encuesta reciente, un 74 por cien de la población considera que la situación ideal para los ancianos es la corresidencia con sus hijos, frente a países del norte donde tan sólo 25 por cien decían lo mismo. Desde esta perspectiva, los cambios en la demografía de la vejez indudablemente traerán grandes transformaciones estructurales en el futuro, pero el bienestar de los ancianos y de la población vulnerable ha sido, es y parece que seguirá siendo una característica fundamental de la familia. 
Otro ejemplo de las dinámicas de solidaridad familiar lo constituye el papel de los abuelos en apoyo de sus hijos y sus hijas que trabajan fuera del hogar o que tienen dificultades para atender a sus hijos. Esta dinámica se ha dado en llamar «el efecto abuela» y es muy característica de la organización familiar del sur de Europa. Todo parece indicar que también fue importante en el pasado, aunque la presencia de abuelos en la sociedad era mucho menor por razones demográficas evidentes. Debido al aumento en que el número de madres solas con hijos y sobre todo de mujeres trabajadoras junto con la mayor presencia de abuelos en la sociedad, la importancia de las intervenciones de los abuelos en la vida de sus hijos y sus nietos no cesa de crecer.

En tercer lugar, los efectos perniciosos de los niveles tan elevados de desempleo en España en los últimos años han sido neutralizados, al menos en parte, por la familia, mediante la prolongación de la corresidencia de padres con hijos mayores o por las transferencias económicas directas e indirectas hacia los hijos sin empleo. En este sentido, las edades tan elevadas de emancipación de los jóvenes españoles no sólo son un indicio de un mercado laboral precario y de una vivienda cara, sino de la fortaleza y eficacia de los apoyos familiares ante una situación de incertidumbre económica. De hecho, desde épocas muy remotas en España la salida del hogar paterno para la inmensa mayoría de la población ha coincidido con el matrimonio. Este patrón no sólo no se ha roto en años recientes, sino que se ha reforzado -aunque con matices-. Por regla general, los españoles suelen pasar de un contexto familiar a otro sin pasar por etapa alguna de independencia. Esta situación contrasta poderosamente con la existente en el norte de Europa donde la emancipación siempre ha tenido lugar varios años antes del matrimonio (hasta 5 ó más), tanto en épocas históricas como actuales. Incluso para su emancipación y la creación de sus propias familias a menudo cuentan con apoyos económicos paternos considerables.

Cabe, por otra parte, considerar la posibilidad de que el apoyo tan fuerte que dan las familias a sus hijos, cuyo indicador principal es la prolongada corresidencia de hijos con padres, haya sido también causa indirecta de los niveles tan elevados de desempleo existentes en España en los últimos años. Es decir, es posible que la vida «cómoda» en casa haya hecho a los jóvenes elevar sus niveles de exigencia ante el empleo, despreciando opciones menos «idóneas» o las que supusiesen asumir los costes de cambiar de entorno, de emigrar. Aunque todo ello pueda resultar bastante especulativo, no cabe descartar esta dimensión de los lazos familiares de cara al funcionamiento del mercado de trabajo en los últimos 
años. Visto desde esta perspectiva, el papel de la familia asumiría una importancia fundamental de cara al bienestar de los jóvenes, como respuesta al desempleo y como causa indirecta del mismo.

Relacionado con esto, pero en sentido diferente, el eje fundamental de las lealtades y de los valores en España ha partido siempre del contexto familiar. No hay indicio tampoco en décadas recientes de cambios al respecto. Es cierto que la autoridad paterna ha disminuido de forma notable, pero sigue siendo muy superior a la existente en otras partes del continente, donde el papel de los padres en la vida de sus hijos se reduce drásticamente a partir de los dieciocho o diecinueve años de edad. Para españoles de todas las edades, la familia sigue siendo un referente fundamental en sus propias vidas.

Por fin, es innegable que el peso de las políticas familiares y de las instituciones públicas en la sociedad española es menor que en otros contextos europeos. Se trata de un hecho incontrovertible. Es interesante observar que hay indicios de que dicho peso haya sido siempre menor en España. No se trataría, pues, de un hecho reciente, sino uno de larga duración. Ello puede desprenderse indirectamente de varias maneras diferentes. Todo parece indicar que en España, desde al menos el siglo XVIII, el peso de la población en instituciones públicas, como hospitales, casas de misericordia, orfanatos, etc., ha sido muy inferior a su peso en países como Inglaterra. Por ejemplo, según el Censo de Floridablanca (1787), aproximadamente 1,4 por cien de la población $>50$ residía en instituciones de caridad, frente a Inglaterra donde el porcentaje era en torno al 5 por cien - es decir, más de tres veces mayor. De hecho, en el norte de Europa la gestión de la pobreza se hacía sobre todo mediante las leyes de pobres, producto de políticas públicas, mientras que en España ello corría a cargo sobre todo de la familia y las instituciones públicas sólo intervenían en situaciones realmente extremas. Muchas dimensiones de pobreza y de marginalidad caían dentro del terreno de la familia. De hecho, siempre se dijo en España que el único verdaderamente pobre era el que no tenía familia.

Este menor peso de lo público o lo institucional en España a lo largo de los siglos se puede explicar por el papel activo de las familias a la hora de asegurar niveles admisibles de bienestar social para sus propios miembros. Desde esta perspectiva, no sería un indicio de retraso en España, sino uno de la existencia de otra forma de resolver los problemas de la vulnerabilidad dentro de la sociedad. Por ello, los especialistas que tratan estos temas harían bien en tener presente que parece que nunca ha habido políticas familiares tan fuertes y activas aquí como en otros 
países europeos. Reconocer esta realidad nos lleva también a reconocer el hecho, tal vez algo desconcertante, de que en la época en que España tenía, por ejemplo, una familia «tradicional» y unos niveles bastante elevados de fecundidad -los años 1960- tampoco tenía políticas sociales tan desarrolladas y coherentes como en otras partes del continente europeo. Es decir, hemos pasado de tener la máxima fecundidad europea sin grandes políticas a tener la menor fecundidad europea sin grandes políticas. Con esto no pretendo argumentar que aquí no hacen falta políticas. Por supuesto que hacen falta, pero conviene no esperar milagros de ellas.

En resumidas cuentas, persiste con claridad la divisoria misma entre norte y sur de Europa, entre familia débil y familia fuerte. Persistencia de posiciones relativas a pesar de la existencia de cambios muy considerables en distintos indicadores sociales, demográficos y económicos. Los que preconizan la homogeneización de la familia en Europa, en mi modesta opinión, están en un error. Se trata de un error basado en la idea de que los procesos de modernización son universales y uniformes. En ese sentido, las especifidades españolas serían fruto de un hipotético retraso o tardanza en dicho proceso de modernización. A mi modo de ver, creo más acertado comprender la familia dentro de un contexto de grandes cambios, pero también de grandes continuidades, tanto entre países como a lo largo del tiempo. Existen presiones en la misma dirección -motivadas en buena medida por factores económicos y realidades demográficas-, pero también diferencias persistentes. Aparte de los ejemplos ya aducidos aquí, se podrían citar otras muchas variables sociales (el suicidio, la cohabitación, la fecundidad fuera del matrimonio, etc.) que enfatizarían el mismo fenómeno. La familia española es, pues, una mezcla de lo nuevo y de lo tradicional, de continuidades y de discontinuidades. Comprender adecuadamente este hecho nos ayudará a situar los cambios recientes dentro de un contexto adecuado.

\section{Reflexiones a propósito de un libro reciente}

La reciente aparición de un libro muy interesante acerca de la familia en Italia nos permite ampliar estas reflexiones acerca de la familia en España. Fare famiglia in Italia. Un secolo di cambiamenti a cargo de Marzio Barbagli, Maria Castiglioni y Gianpiero Dalla Zuanna (Bologna, Il Mulino, 2003) supone una contribución importante a nuestro conocimiento de la familia en Italia y, dadas las similitudes entre las formas familiares en Italia y en España, nos termina planteando temas extrema- 
damente pertinentes que afectan a la familia aquí. Los autores emprenden su estudio desde una perspectiva histórica y sociológica y centran sus análisis en cuatro temas centrales para la vida familiar: los procesos de emancipación de los jóvenes, el matrimonio (la edad al casarse, la boda, el banquete de bodas y el viaje de novios), la corresidencia después del matrimonio y los procesos reproductivos. Es decir, sólo abordan una parte de la vida familiar, si bien se trata de una parte clave de la misma.

En todos estos campos, los autores encuentran indicios de un fortalecimiento reciente en el papel de la familia dentro de la sociedad italiana. Persisten los tradicionales lazos familiares fuertes y hasta van en aumento. En muchos aspectos, los autores de este estudio constatan que los vínculos familiares en Italia nunca han sido tan fuertes como en los años recientes. Todo ello se inserta dentro de un contexto de persistencia de formas familiares marcadamente distintas a los vigentes en el norte de Europa, aunque las tendencias generales de diversos indicadores sean similares en todas partes. En este sentido, sus resultados no distan mucho de otros similares que han aparecido en muchos estudios recientes de la familia en España.

Los autores encuentran que en Italia la emancipación de los jóvenes y el matrimonio se producen cada vez más tardíamente. Una vez casados los jóvenes, más de dos tercios de ellos establecen su residencia cercana a la de sus progenitores. Existe un verdadero auge de la vivienda en propiedad, en lugar de la de alquiler, y los padres suelen intervenir activamente en apoyo a la compra de la primera vivienda. Los estudios duran cada vez más e invariablemente son costeados por los padres. Los autores encuentran que los padres también intervienen activamente en el cuidado de sus nietos, así constatando la existencia del llamado «efecto abuela» tan conocido en España. Todos estos parámetros de la vida familiar, comunes a buena parte del sur de Europa, indican un papel de la familia en auge y el reforzamiento de los lazos familiares, ya de por sí fuertes en el mundo mediterráneo. Se puede afirmar que en muchos aspectos casi nunca ha tenido la familia tantas relaciones y lazos tan fuertes como en la actualidad.

Se trata de una situación ciertamente irónica a tenor de la «muerte de la familia» tan en boga en los años 1960-1980 entre sociológicos y otros llamados expertos. Todavía es posible, hoy en día, oír que la vigencia de la familia se debe a un supuesto déficit de modernización. De igual manera, la persistencia en Europa de zonas de familia fuerte (la Europa meridional) y de familia débil (la Europa central y septentrional) a menudo se considera como vestigio de retraso de los países del sur en el proceso 
de modernización. Todo ello se afirma, aún a sabiendas de que los países del sur llevan décadas plenamente modernizadas.

Pues, contrario a tantos augurios, la familia no ha desaparecido en absoluto. Ha cambiado pero no ha perdido ni un ápice de su importancia. Mientras ha perdido ciertas prerrogativas tradicionales (sobre todo las relacionadas con la autoridad paterna), ha asumido otras, muchas de ellas de naturaleza económica y de solidaridad para con sus miembros necesitados, bien sea jóvenes o ancianos. Cabe afirmar que en la actualidad su capacidad de influencia en la vida de sus miembros está más fuerte y visible que nunca. Esta flexibilidad no es nada sorprendente en una institución tan antigua como la familia, aunque tal vez lo sea más el aumento en su influencia que ha tenido lugar en estos últimos años. Esta situación se ha debido a una serie de factores que han afectado muy directamente las funciones de la familia. Un mercado de trabajo endeble, la prolongación del período de escolarización de los jóvenes, la actividad laboral de las mujeres y una insistencia en una vivienda en propiedad en lugar de una en alquiler han contribuido todos ellos a hacer a los jóvenes más dependientes de sus propias familias. Las familias han respondido a estos retos, acudiendo en apoyo a sus miembros jóvenes.

La constatación tan rotunda de esta fortaleza y vigencia de los lazos familiares merece otras reflexiones más generales, menos pegadas a las realidades inmediatas de las sociedades italianas y españolas. No cabe dudar ni de la fuerza de estos vínculos ni de su vigencia. Se trata de una realidad incontrovertible. Pero no se trata de una realidad neutral, ya que tiene implicaciones tanto positivas como negativas para las sociedades del sur de Europa. Entre aquellas, cabe destacar que la intervención activa de la familia en la vida de los jóvenes tiene lugar en un momento difícil de sus vidas. En una situación potencialmente negativa (desempleo, desaliento, falta de opciones) y en ausencia de políticas públicas intervencionistas como las existentes en muchas sociedades del norte de Europa, interviene la familia para minimizar los obstáculos en la transición a la vida adulta. Por otra parte, este apoyo familiar facilita la entrada de la mujer en el mercado de trabajo, sobre todo por el intervencionismo de los padres de cara a los hijos de sus hijos. El enorme incremento en las tasas de actividad económica de mujeres en los últimos dos o tres décadas difícilmente se podría comprender sin este apoyo por parte de sus familias, ayudándolas a simultanear trabajo y reproducción. Aunque este aspecto puede tener su lado negativo (ver más abajo) y la ayuda dista mucho de resolver todos los problemas de las madres trabajadoras, indudablemente la familia ha tenido algo que ver con esta transformación social de tan enormes consecuencias. 
El apoyo familiar, por otra parte, ha permitido alcanzar mayores niveles de educación entre los jóvenes, con la posibilidad, al menos en teoría, de mejores colocaciones profesionales. No hay que olvidar que no sólo costean las familias los estudios de sus hijos, sino también les permiten continuar residiendo en casa mientras prosigan sus estudios. De esta forma, la familia costea doblemente la formación de sus hijos ya mayores, mediante el pago de las matrículas y la asunción por parte de las familias de los gastos habituales que incurren los hijos en su quehacer diario. Relacionado con todo ello, una de las consecuencias más notables de este intervencionismo familiar es que permite a los jóvenes disfrutar de un nivel de vida bastante superior a la que hubiesen tenido de haber estado viviendo por su cuenta, gracias a sus propios ingresos. Es más, mientras el desaliento causado por los enormes niveles de desempleo corresponde por entero a los jóvenes, los costes económicos del mismo tocan en su mayoría a las familias. Finalmente, entre los aspectos positivos de esta vigencia de la familia cabe citar a la familia misma que inesperadamente ha encontrado una enorme constatación de su propia vigencia y utilidad. Se puede afirmar que, desde las décadas centrales del siglo XX, nunca se ha sentido tan segura de si misma la institución familiar. Además, en este terreno la familia ha venido a cubrir una necesidad social que en algunos países corresponde en buena medida a las políticas públicas y en otros no se encuentra cubierto más que por el mercado de trabajo y las condiciones económicas.

A pesar de estos aspectos incuestionablemente positivos relacionados con el papel de la familia, sería miope no darse cuenta de su lado negativo, tanto para los jóvenes como para las familias y para la sociedad en su conjunto. El primero de entre ellos es el hecho de que la falta de salidas profesionales para jóvenes y el consiguiente intervencionismo de las familias en sus vidas conllevan una evidente falta de autonomía entre los jóvenes y una mentalidad de dependencia más allá de lo que sería deseable. Aunque pueda parecer sorprendente a primera vista, dadas las relaciones tan cordiales existentes, por regla general, entre padres e hijos así como el superior nivel de vida de los hijos es muy legítimo preguntarse si de verdad podemos hablar de autonomía de los individuos cuando en lo económico no hay autonomía alguna. ¿Es necesaria una autonomía individual para el bienestar íntegro, para el sentido de la responsabilidad y para la capacidad de pensar y actuar con independencia de criterio de los individuos? Nos inclinamos a pensar que sí que es necesario y que esta etapa de prolongada dependencia de hijos con respecto a sus padres tendrá consecuencias a medio y largo plazo nada positivas para los individuos y para la sociedad misma. 


\section{El cambio familiar en España en el marco de la ...}

En segundo lugar, los perfiles concretos de este protagonismo implican que corresponde a la familia costear este apoyo a sus hijos. A pesar del hecho de que en los países meridionales de Europa siempre ha sido relativamente tardía la emancipación, no es en modo alguno similar el coste cuando los hijos se marchaban de casa a los 22-25 años, a menudo sin haber hecho estudios universitarios, que cuando se marchan entre los $28 \mathrm{y}$ 32 años, habiendo terminado sus estudios universitarios y a menudo con títulos de postgrado. Es decir, la estancia de los hijos en sus hogares paternos dura más y es mucho más costosa que antes. Además, como bien ha puesto de manifiesto este estudio sobre la realidad italiana y como se da en la sociedad española, cuando se emancipan los jóvenes suelen recibir abundante ayuda de sus familias tanto para sus bodas como para facilitar el acceso a su primera vivienda, habitualmente en propiedad. En estos momentos, es difícil estimar las implicaciones que tiene todo ello para las economías familiares, salvo en sus efectos inmediatos. Pero podemos sospechar que dichos efectos serán importantes. Como mínimo, la capacidad de ahorro de las familias se encontrará hipotecado -o al menos retrasado- por este proceso, hecho que tendrá implicaciones para el bienestar de los padres en el presente y sobre todo cuando sean ancianos. Conviene recordar, al respecto, todas las dudas e incertidumbres que rodean y rodearán la vejez en el presente y en el futuro, sobre todo referidas a los sistemas de pensiones, a la salud en la vejez y, tal vez lo más importante, a la duración de la vida. ¿Están hipotecando una parte de su futuro los padres al apoyar tanto a sus jóvenes? Es evidente que ello no es cierto del todo, pero igualmente evidente es el hecho de que dinero que se gasta hoy no existe para mañana. Relacionado con este mismo tema, cabe preguntarse si dentro de varios años existirán presiones familiares mayores a los hijos para hacerse cargo de las necesidades de sus progenitores y si estarán ellos dispuestos a asumir estas responsabilidades. No sabemos responder adecuadamente a estos interrogantes, pero es indudable que el apoyo de padres a hijos en estas cosas sí que tendrá repercusión a largo plazo tanto para unos como para otros.

Por otro lado, cabe la posibilidad de que tanto apoyo a los jóvenes sea un desincentivo para ellos a la hora de buscar trabajo y lograr su propia autonomía. Al vivir cómodamente, muchos jóvenes podrían encontrarse reticentes a la hora de aceptar empleos o situaciones residenciales inferiores a sus aspiraciones. Es decir, el apoyo familiar puede dificultar decisiones que impliquen un menor nivel de vida o de seguridad. Es lícito preguntar si la familia y los lazos familiares tienen algo que ver con la reticencia de muchos jóvenes a utilizar el recurso de la migración a fin de 
optimizar sus opciones para conseguir trabajo, con la insistencia entre muchos jóvenes de acceder a una vivienda en propiedad en lugar de una en alquiler, a menudo compartida con otros, o con la aversión al riesgo tan evidente en muchos jóvenes. Por otra parte, en un artículo reciente, Massimo Livi Bacci ha relacionado los niveles bajísimos de fecundidad en el sur europeo precisamente con una cultura de comodidad y de dependencia entre los jóvenes, que les lleva a retrasar al máximo el comienzo de sus propias vidas reproductivas. Todos estos son interrogantes preocupantes que van al meollo de algunas de las grandes preocupaciones sociales. Si nuestra respuesta ante ellos corrobora que la familia, con todo su apoyo y dedicación, está facilitando estos tipos de comportamiento, no tendríamos más remedio de dejar de ver a la familia como parte de la solución y situarla como parte del problema.

Es evidente que estas cuestiones sociales son complejas y no existen explicaciones unilaterales. También es evidente, no obstante, que es imposible realizar un análisis social convincente sin tener presente el papel de la familia y de los lazos familiares. Una cuestión menos clara es el protagonismo que hay que atribuir a la familia en los procesos sociales ya mencionadas. Por un lado, cabe la posibilidad de atribuirle un gran protagonismo en estos procesos, situándole como un factor causal fundamental. Por otro, en cambio, el papel de la familia se puede ver como una respuesta a procesos desencadenados por otras fuerzas económicas y sociales. En este caso el verdadero protagonismo lo tendría el desempleo y el empleo inestable, las dificultades en el mercado de la vivienda, las aspiraciones de los individuos, pero no la familia. Es imposible responder con seguridad a este interrogante, aunque sospecho que la causalidad va en ambas direcciones. La familia como recurso de defensa, de colchón, ante las incertidumbres sociales es incuestionable. Asimismo, sin embargo, ¿qué duda cabe que la familia desempeña un papel crucial en la creación de las aspiraciones y las exigencias entre los jóvenes, y en su aversión al riesgo?

¿Qué va a pasar el día de mañana? Es indudable que muchos jóvenes consideran que esta ayuda familiar que están recibiendo es una ayuda 'estructural', por así decirlo, y por lo tanto es gratis. ¿Lo es de verdad? Me parece que no. En cualquier sociedad, los lazos, bien sean familiares o de otro tipo, siempre son recíprocos; exigen reciprocidad. ¿Cómo van a cumplir los jóvenes su parte del pacto? Es evidente que no estamos en condiciones de responder con una mínima de confianza a este interrogante, aunque no ponemos en duda su evidente pertinencia. Lo que sí nos parece seguro es que las relaciones intergeneracionales propias de las fami- 
lias fuertes continuarán cuando los padres de ahora se conviertan en ancianos de mañana. Pero habrán cambiado con respecto a la actualidad por muchas razones, una de las cuales relacionada con la situación vigente en los últimos 20 años en España.

\section{Algunas consideraciones acerca del futuro de la familia}

Aparte de estas consideraciones generales, hay poco que podemos afirmar con seguridad acerca del futuro de la familia en España. Únicamente, tal vez, en aspectos relacionados con la demografía existe posibilidad de prever algo del futuro ya que podemos tener alguna certeza de que las personas, por ejemplo, que hayan nacido en los últimos años estarán presentes en la población española durante muchas décadas. El presente y el futuro demográfico de España afecta y afectará muy directamente a la institución familiar así como a la sociedad en su conjunto. No cabe distinguir en este sentido entre sociedad y familia, salvo en cuestiones de escala.

En España en los últimos veinticinco años hemos entrado en un mundo demográfico realmente desconocido, con una reducción drástica en la fecundidad y en el número de nacimientos. Nos estamos adentrando en un mundo probablemente regresivo en lo demográfico y de rápido envejecimiento de la sociedad. Las familias van a resentir estos procesos a la hora de cumplir con su misión tradicional de solidaridad o de socorro a sus miembros vulnerables, simplemente por el hecho de que el número de ancianos por hijo va a cambiar. Vamos a pasar de una situación donde existen varios miembros de la familia por cada anciano vulnerable, a otra donde esta ratio se invierte. Ello va a tener una gran importancia a largo plazo ya que afectará profundamente a la capacidad de la familia para cumplir uno de sus papeles centrales.

En un futuro muy próximo, este mismo proceso de reducción en el número de nacimientos va a llevar a una disminución de la fuerza de trabajo en España. Estamos pasando de una época donde predominaba una oferta de trabajo abundante, sobrante en muchos momentos, a otra de escasez de la fuerza de trabajo. Ello va a tener cuatro implicaciones que ya se vislumbran en la actualidad: un aumento en la intensidad migratoria, un aumento en las tasas de actividad económica de las mujeres, un progresivo retraso en la edad de jubilación de los distintos sectores de la población y la cada vez mayor dificultad para sostener las prestaciones sociales que han venido caracterizando el Estado de bienestar. Se trata de 
cambios previsibles en los próximos quince o veinte años. Todos ellos van a incidir directamente tanto en la sociedad como en la vida familiar.

Una situación en la que hay una abundancia de población anciana, que percibe pensiones y cuyos costes en salud resultan relativamente elevados, junto con una población en edad laboral con tendencia a disminuir, difícilmente puede acarrear optimismo económico alguno. La sociedad española sólo acaba de internarse en el debate público acerca de esta cuestión, muchos años después de que hubiera debido comenzar. El retraso en la edad de jubilación es una de las soluciones barajadas para un futuro más o menos próximo. Otra es el aumento en la actividad económica de las mujeres. Sin duda ambos recursos se pondrán en práctica en los próximos años. Pero ante la magnitud de los cambios previsibles, es difícil pensar que sean más que remedios parciales.

La inmigración de trabajadores de otros países es ya una realidad en España y en años futuros esta inmigración no hará sino aumentar. Su capacidad para rellenar adecuadamente el hueco dejado por tanta escasez de mano de obra española, no obstante, suscita dudas muy razonables. La llegada masiva de inmigrantes, además, terminará planteando problemas de integración dentro de la sociedad española difíciles de imaginar en estos momentos. Por el contrario, sin embargo, cabe preguntarse que si no llegan, ¿dónde se encontrará la mano de obra precisa para hacer funcionar la economía española, amén de los sistemas de pensiones o de un estado de bienestar de tamaño reducido, pero al menos existente? De esta manera, la realidad futura de la familia, caracterizada por crecientes dificultades para socorrer a sus miembros necesitados, y una situación social, con creciente escasez de mano de obra y abundancia de población dependiente, seguirán cursos paralelos e interdependientes.

El problema español es, claro está y con matices, el problema de todos los países desarrollados de la Europa occidental. Se trata de un problema agravado aquí por la rapidez de los cambios demográficos que empezaron tarde pero ocurrieron con mucha mayor intensidad que en otros países. Pueden existir otros escenarios futuros diferentes, como por ejemplo un aumento importante en la productividad económica o que el desarrollo tecnológico desemboque en una disminución de nuestra dependencia de la fuerza de trabajo para crear riqueza. Pero estas salidas no son probables. Tener una población anciana numerosa y en buena medida dependiente en lo económico y lo social, estar entrando en una larga fase de previsible disminución de la fuerza de trabajo existente en el país posiblemente a pesar de los aportes migratorios, y tener una sociedad y un sector público que no parecen reaccionar ante los retos de asegurar la re- 


\section{El cambio familiar en España en el marco de la ...}

producción de la sociedad, no prometen nada bueno para la economía y la sociedad españolas en estos inicios del siglo XXI. A pesar de estar en la cúspide histórica de su riqueza, de haber culminado un siglo de grandes avances, y de haber logrado niveles desconocidos de bienestar social, nos tememos que España no ha podido iniciar el nuevo siglo con peor pie.

\section{Notas}

1 Una primera versión de estas ideas apareció en: «Familia y sociedad en el mundo occidental desarrollado: una lección de contrastes», Revista de Occidente, n. ${ }^{\circ}$ 199, Diciembre de 1997, pp. 112-132. Una versión más elaborada se encuentra en (1998) «Family ties in Western Europe: Persistent contrasts", Population and Development Review, vol. 24, 2, pp. 203-234. Existe una versión española de este último escrito: «Lazos familiares en la Europa Occidental: una lección de contrastes perdurables», en M.A. Durán, et.al. (eds), Estructura y cambio social. Homenaje a Salustiano del Campo, Madrid, Centro de Investigaciones Sociológicas, 2001, pp. 313-346. 